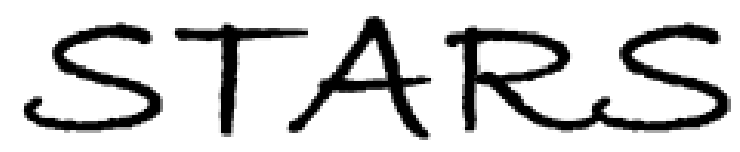

University of Central Florida

STARS

$1-1-2003$

\title{
Spatial variability of surface rainfall as observed from TRMM field campaign data
}

Saswati Datta

W. Linwood Jones

University of Central Florida

Biswadev Roy

Ali Tokay

Find similar works at: https://stars.library.ucf.edu/facultybib2000

University of Central Florida Libraries http://library.ucf.edu

This Article is brought to you for free and open access by the Faculty Bibliography at STARS. It has been accepted for inclusion in Faculty Bibliography 2000s by an authorized administrator of STARS. For more information, please contactSTARS@ucf.edu.

\section{Recommended Citation}

Datta, Saswati; Jones, W. Linwood; Roy, Biswadev; and Tokay, Ali, "Spatial variability of surface rainfall as observed from TRMM field campaign data" (2003). Faculty Bibliography 2000s. 2560.

https://stars.library.ucf.edu/facultybib2000/2560

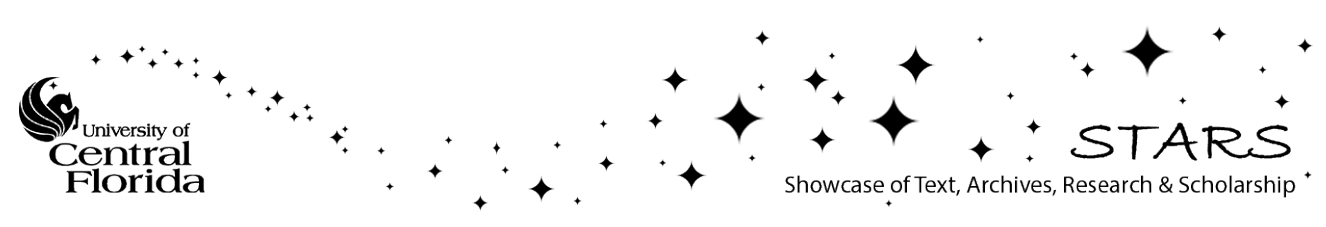




\title{
Spatial Variability of Surface Rainfall as Observed from TRMM Field Campaign Data
}

\author{
SASWATI DATTA \\ Joint Center for Earth Systems Technology, University of Maryland, Baltimore County, Baltimore, Maryland \\ W. LINWOOD JONES \\ School of Electrical Engineering and Computer Science, University of Central Florida, Orlando, Florida \\ BISWADEV ROY \\ Science Systems and Applications, Inc., Seabrook, and Mesoscale Processes Branch, NASA Goddard Space Flight Center, \\ Greenbelt, Maryland \\ Ali TOKAY \\ Joint Center for Earth Systems Technology, University of Maryland, Baltimore County, Baltimore, Maryland
}

(Manuscript received 23 March 2002, in final form 25 August 2002)

ABSTRACT

\begin{abstract}
The spatial variability of surface rainfall over 5- and 30-day time periods is observed, and it is found that the spatial decorrelation length of precipitation is comparable to the size of a single surface gauge network. The observed variability is found to affect radar-derived precipitation estimation, particularly if it is based on calibration using rain gauges. The radar subgrid-scale variability is also observed using some redundant and finerscale gauge networks deployed during the Tropical Rainfall Measuring Mission (TRMM) ground-validation field campaigns. Based upon statistical analysis and a point-based decision-making system, a best-suited spatialtemporal filtering technique is suggested and, when applied to match radar data with any other surface observation, is found to reduce bias.
\end{abstract}

\section{Introduction}

A quantitative estimation of rainfall amount from a radar requires a suitable interpretation of the radar reflectivity $Z$ relative to the rain rate $R$ measured at the surface. In other words, one has to use a suitable $Z-R$ relationship to estimate the surface rainfall from the radar observation. Since the first inception of radar as a tool for quantitative precipitation measurement, numerous theoretical and empirical $Z-R$ relations have been used (Atlas et al. 1997; Battan 1973). The most widely used form of the $Z-R$ relation is a power law:

$$
Z=A R^{b} .
$$

This power-law relation is a natural consequence of the lognormality of the probability distribution functions (PDF) of $Z$ and $R$ (Atlas et al. 1997). The climatologically accepted values of $A$ and $b$ are 300 and 1.4, re-

Corresponding author address: Dr. Saswati Datta, Joint Center for Earth Systems Technology (JCET), University of Maryland, Baltimore County, ACIV Wing A, Rm 114, 1000 Hilltop Circle, Baltimore, MD 21250.

E-mail: sdatta@umbc.edu spectively, when $Z$ is expressed in linear units $\left(\mathrm{mm}^{6}\right.$ $\mathrm{m}^{-3}$ ) and $R$ is in millimeters per hour.

Because the spatial and temporal variability of the raindrop size distribution is enormous and the vertical profile of reflectivity is not usually known in real time, it is a common practice to adjust the radar-derived rain estimation with surface rain gauges. There are five limitations to this approach, however:

1) The spatial and temporal resolution of radar and gauge differ widely. The resolution volume of radar is about nine orders of magnitude greater than the resolution volume of a gauge. A gauge is a single point measurement with respect to the radar pixel. Rain rate can easily vary by a factor of 10 within a 10-min period or within a 2-km distance (Joss and Waldvogel 1990). Given the spatial variability of the precipitation, is a single-point gauge measurement representative of a volume-averaged radar pixel value?

2) The radar and gauge are not sampling at the same frequency (Le Bouar et al. 2001), which introduces the problem of averaging or time synchronization of the two observations to be compared. 
3) There are issues of data quality for both radar and gauge observations. For radar, uncertainties in measurement arise for different reasons, such as

- uncertainties in reflectivity measurement caused by hardware calibration and stability issues,

- attenuation by atmospheric gases and raindrops (however, for wavelengths greater than $5 \mathrm{~cm}$, neither is significant),

- beam blockage caused by topography and curvature of the earth, and

- effects of ground clutter and anomalous propagation. (Under an abnormal moisture gradient of the atmosphere, the radar beam bends toward the ground after reflection at the hydrolapse. This effect generates a strong echo and is called the anomalous propagation, or AP, contamination of the radar scene. Sometimes birds or even bugs create false echoes. These clutter effects and false echoes pose a real problem to quantitative estimation of precipitation from radar.)

In the case of rain gauges, there are different sources of errors. Particularly for the tipping-bucket type of gauges, there are problems with false, multiple, or undetected tips at low rain rate. Also, there might be undercatch because of wind effect (Neff 1977). There also are factors such as mechanical or electrical failure of the gauge and datalogger system in the field.

4) The spacing between the networks and even between the gauges might be too large to resolve the variability of actual precipitation systems, which could introduce error during adjustment.

5) The altitude difference between radar observation and surface gauge observation is another important factor.

These issues are discussed in a detailed uncertainty analysis of ground-based radar products by Habib and Krajewski (2002).

The main objective of this paper is to discover the spatial variability of surface rainfall in radar-grid-scale, as well as in subgrid-scale, resolution and to determine how this variability is affecting radar retrievals. Also, an attempt has been made to provide an improved method to match radar with surface observations to yield better rainfall products. The entire investigation is conducted for the Melbourne, Florida, Weather Surveillance Radar-1988 Doppler (WSR-88D) during the period of the Texas and Florida Underflights Experiment, phase B (TEFLUN-B). A brief description about the data and the region of study is given in the next section.

Section 3 discusses the observed variability in the data during single-event, 5-day, and 30-day timescales. In section 4, different filtering techniques are described and are evaluated for better spatial-temporal matching and calibration of radar data with surface observations. A brief discussion of the results is given at the end.

\section{Data}

The Tropical Rainfall Measuring Mission (TRMM) has an extensive validation program. The ground-validation $(\mathrm{GV})$ component of that program is dedicated to obtaining an independent rainfall estimate from surfacebased radar and gauges, and there are four primary GV sites over the Tropics. The National Weather Service of the National Oceanic and Atmospheric Administration (NOAA) operates a 10-cm WSR-88D at Melbourne, Florida. This radar, designated as KMLB, is used for the TRMM ground-validation campaign, and the analysis presented here uses TRMM GV rainfall products from the KMLB radar.

Operational GV products are produced at three levels (Kummerow et al. 2000; Marks et al. 1999). Level-1 processing includes quality-control steps to remove clutter or AP contamination of the raw reflectivity data. At level-2 processing, quality-controlled reflectivity data are suitably matched with collocated quality gauge data to estimate a suitable $Z-R$ relation. This $Z-R$ relation is then applied to create instantaneous rain-rate maps. Convective and stratiform classification of rainfall is also performed during level-2 processing, and collocated maps with respective flags are produced. The instantaneous rain-rate maps are integrated in level 3 to generate accumulated rainfall products. The analysis presented here uses mostly GV level- 2 and -3 rainfall products. These products are generated as maps in a 2 $\mathrm{km} \times 2 \mathrm{~km}$ Cartesian grid, with the radar at the center in a tilted plane. The lowest elevation map has a $0.48^{\circ}$ tilt from the horizon. The entire size of the map is 151 $\times 151$ pixels, which spans an area of $150-\mathrm{km}$ radius around the radar.

Another integral component of TRMM validation is its series of field campaigns. The first of that series was TEFLUN, which was conducted from 1 April to 15 May 1998 at the Houston, Texas, GV site. TEFLUN-B was conducted from 1 August to 27 September 1998 and focused on central and southern Florida, which encompasses the Florida GV site. During TEFLUN-B, a dense rain gauge network (DRGN) was installed at Holopaw, Florida, about 40-km west-southwest of the Melbourne (KMLB) radar. In addition, 13 more gauges were added to the existing National Aeronautics and Space Administration (NASA) Kennedy Space Center (KSC) network to increase the gauge density there. At the heart of the DRGN, a master GV site was chosen, at which multiple sensors were installed for simultaneous and redundant observation of precipitation events. The sensors at this master GV site include one Joss-Waldvogel-type disdrometer (JWD), two 2-dimensional video disdrometers (2DVD: one from NASA and one from The University of Iowa), one Applied Physics Laboratory (APL) disdrometer, one vertical-pointing ultrahigh-frequency (UHF) profiler from NOAA, and several redundant tipping-bucket gauges (Tokay et al. 2001; Habib and Krajewski 2002). 


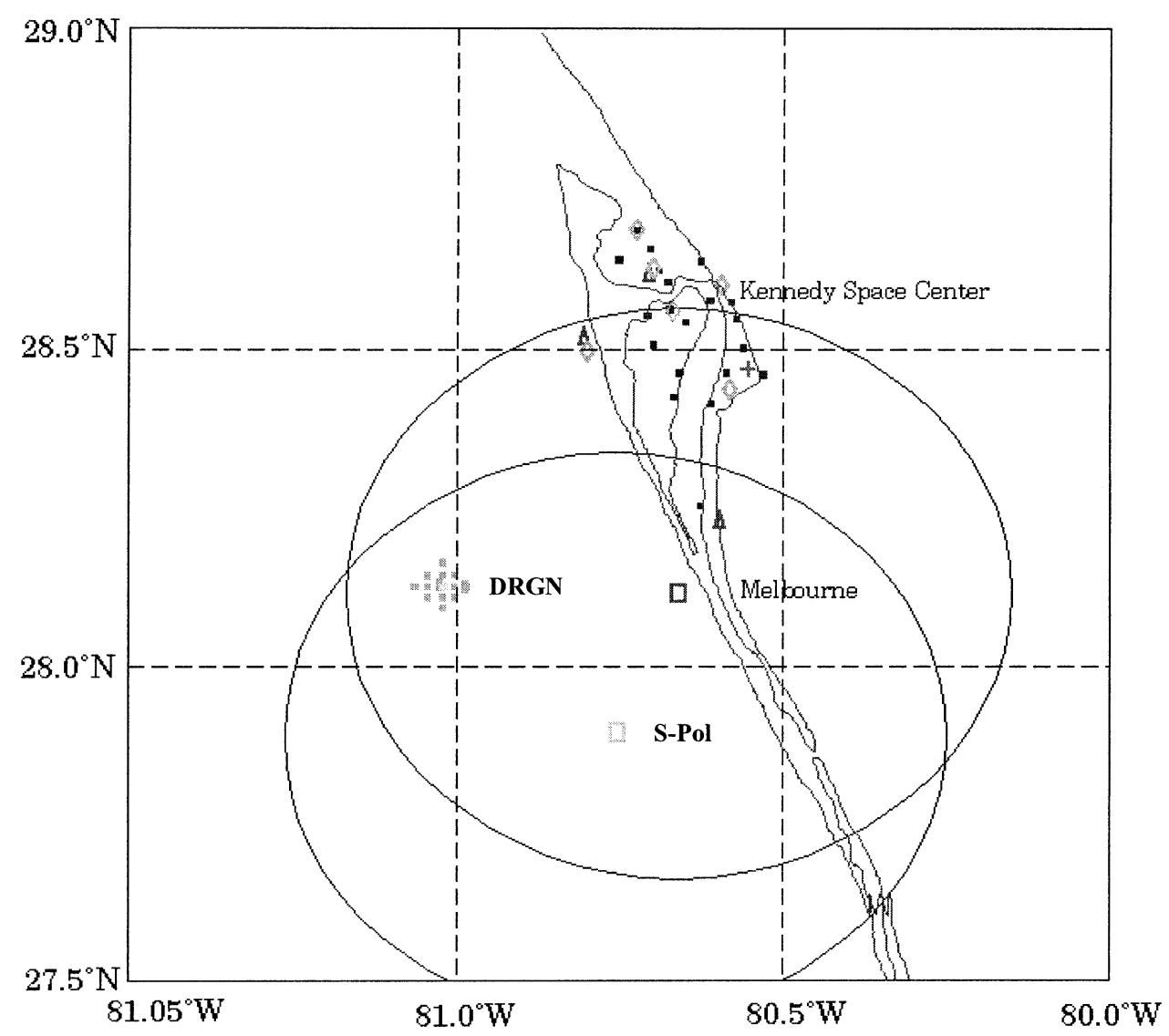

FIG. 1. Map showing the TEFLUN-B experimental coverage area.

An S-band dual-polarized Doppler radar (S-Pol) from the National Center for Atmospheric Research was also installed about $40 \mathrm{~km}$ south of the KMLB radar (Brandes et al. 2002). Figure 1 gives a map of the TEFLUN$\mathrm{B}$ coverage area. This multitude of sensors in a dense observation network during TEFLUN-B presented an opportunity to perform a detailed study of variability of rainfall over that region. The objective of the research presented in this paper is mainly to understand the spatial variability of precipitation observed during the TEFLUN-B period and to make use of most of the groundbased sensors available during the experiment.

\section{a. Timescale}

The analysis is made at three different timescales: 1) event scale; 2) 5-day, or pentad, timescale; and 3) 30day, or monthly, timescale. These timescales are selected following TRMM standard product specification (Marks et al. 1999).

For event-scale analysis, two significant rain events during TEFLUN-B are chosen. One was on 3 September 1998 (yearday 246) between 1730 and 1842 UTC, and the other was on 7 September 1998 (yearday 250) between 1910 and 2230 UTC. We will refer to these events as $\mathrm{J}-246$ and $\mathrm{J}-250$, respectively.

\section{b. Region of interest}

Two dense gauge networks in the KMLB radar mask, one at DRGN and the other at KSC, are the main regions of interest for the entire study. The parts of the radar mask with grid and gauge locations are shown in Fig. 2 for those two regions. The DRGN has three dense microclusters of gauges noted as $101 \mathrm{C}, 112 \mathrm{C}$, and 108 $\mathrm{C}$ in Fig. 2b. Each one of them contains a triplet of gauges (the 101 cluster has one additional redundant gauge) placed about $500 \mathrm{~m}$ apart within a single radar grid box. In addition to the network-scale analysis, subnetwork-scale analyses are also performed in this paper.

For the KSC network, five subnetworks, K1 (12, 14, and 15), K2 (29, 32, and 34), K3 (8 and 9), K4 (17 and 18 ), and K5 (19 and 21), have been identified for analysis. All of the subnetworks are marked by hatched boxes in Fig. 2. The main emphasis of the current work is to understand the spatial variability of precipitation as observed using different sensors. Quality of the data used is an important factor for that purpose. Only gauges that passed the automatic quality control procedure, hereinafter referred to as AQC gauges, are used for the current study.

For event-scale observation, the region is further localized to the DRGN master GV site. The inset in Fig. 
(a)
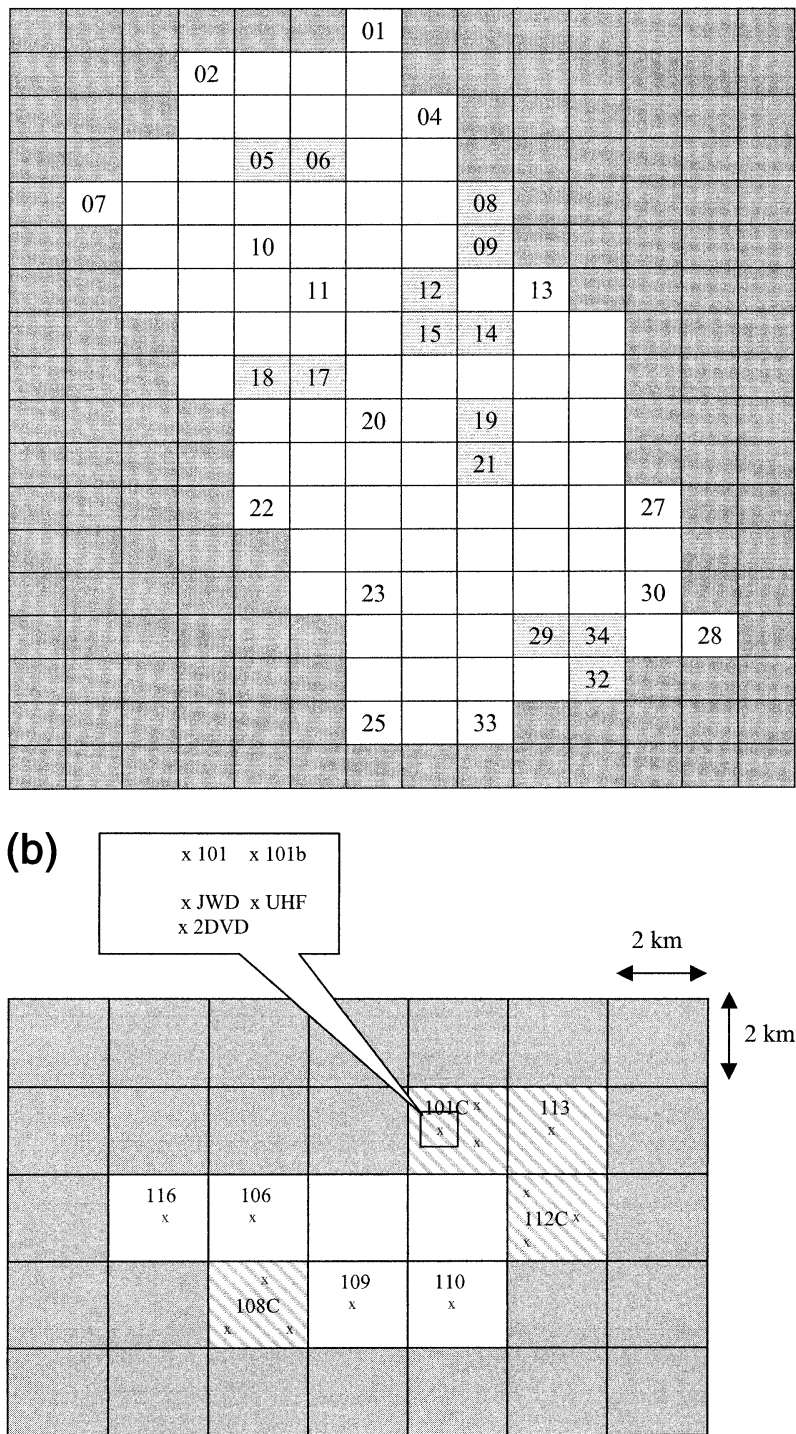

FIG. 2. (a) Region of interest over KSC network $\left(28 \times 36 \mathrm{~km}^{2}\right)$ The size of a grid box is $2 \mathrm{~km} \times 2 \mathrm{~km}$. (b) Region of interest over DRGN $\left(14 \times 10 \mathrm{~km}^{2}\right)$. The gauge spacings are not drawn exactly to scale.

2 represents a schematic diagram of different sensor locations in the master GV site and its relative position in the KMLB radar pixel.

\section{Observed variability}

a. Event-scale variability

\section{1) J-246 Event}

The 3 September 1998 rain event is a typical convective rain event that started at 1732 and ended at 1844 UTC, with a brief dry interval of 5 min between 1757 and 1802 UTC. The observed rain characteristics and
TABLE 1. Rainfall accumulation ( $\mathrm{mm}$ ) during J-246 and J-250 events (WSR-88D is Melbourne, FL, radar used for GV; 101 is gauge at DRGN 101 site; 101b is redundant gauge next to $101 ; 2 \mathrm{DVD}$ is two-dimensional video disdrometer; and JWD is Joss-Waldvogeltype disdrometer).

\begin{tabular}{cccccc}
\hline \hline Event & WSR-88D & 101 & $101 \mathrm{~b}$ & 2DVD & JWD \\
\hline J-246 & 3.40 & 5.59 & 5.84 & 5.63 & 5.17 \\
J-250 & 5.11 & 6.60 & 6.10 & 7.27 & 5.90 \\
\hline
\end{tabular}

drop size distribution during this event are described by Tokay et al. (2001), and the total rain accumulations, as measured by different sensors, are given in Table 1 .

Figures $3 a, b$ show the corresponding reflectivity and rain-rate time series, respectively. When operated in precipitation mode, the KMLB radar scans every 5-6 min; as a result, it missed the peak of the event, as is evident from the reflectivity time series. Also, at times the WSR88D measured reflectivity differed from other instruments by as much as $18 \mathrm{dBZ}$.

A comparison between the WSR-88D and gauge rainrate time series reveals some interesting details. The most significant observation is that, whereas this event actually has two peaks, the WSR-88D misses the first, significantly underestimates the second, and shows a sudden peak around 1830 UTC at which time no other

(a)

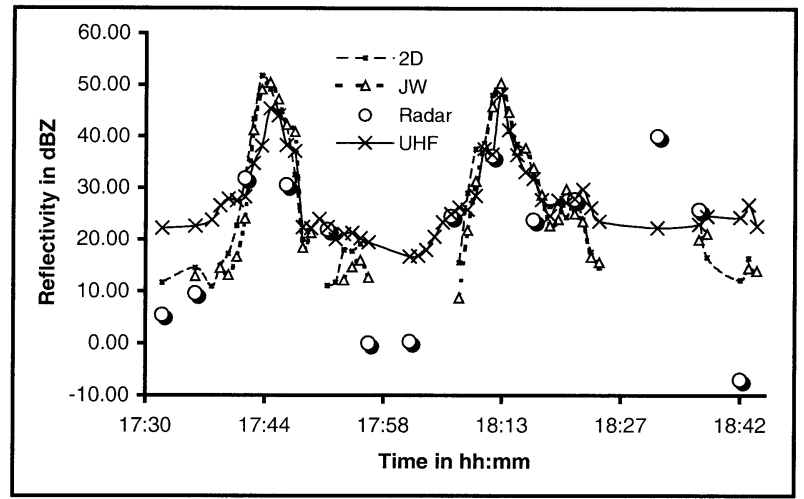

(b)

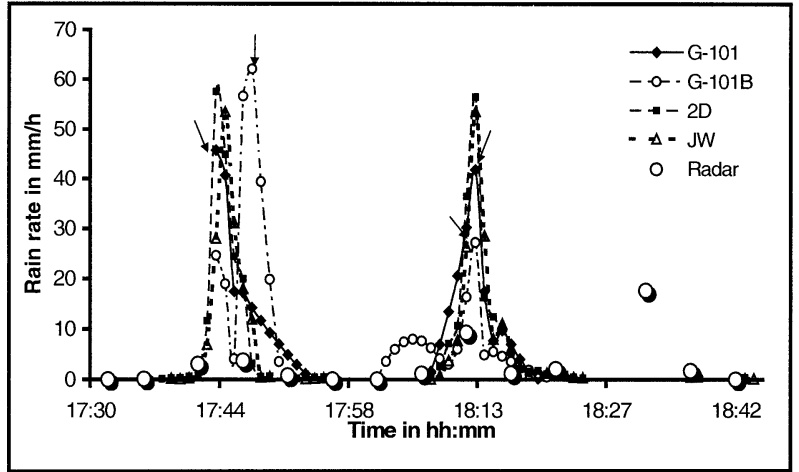

FIG. 3. (a) Reflectivity and (b) rain-rate time series for the J-246 event. 
(a)

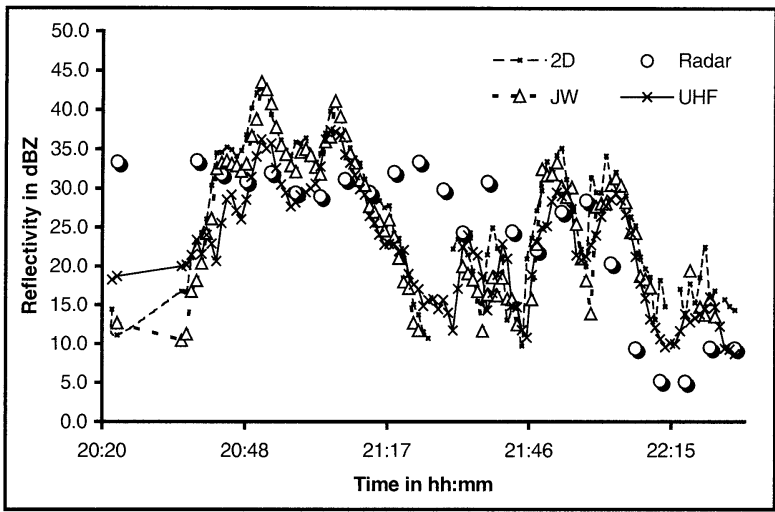

(b)

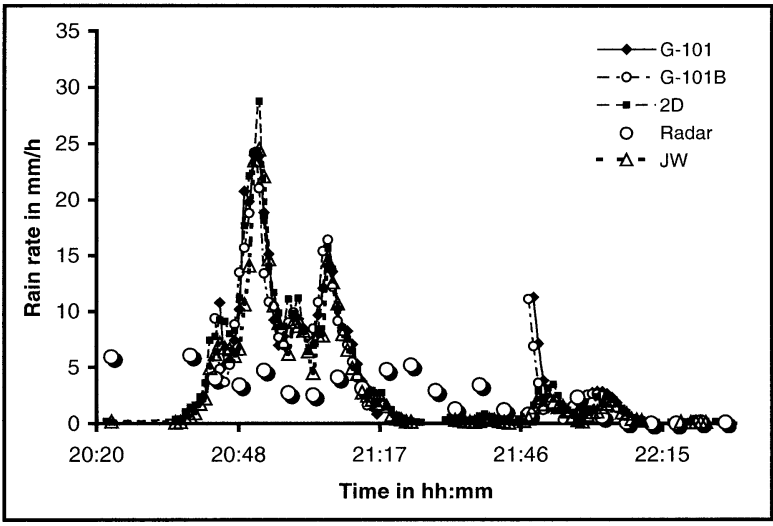

FIG. 4. Same as Fig. 3 but for the J-250 event.

surface-based instrument measured any rain. Another interesting observation is the difference in rain-rate measurement by the redundant gauges 101 and 101b, which are spaced $15.24 \mathrm{~m}$ apart. The $101 \mathrm{~b}$ gauge measures its first peak at 1748 UTC, more than 4 min later than the other instruments. This observation is interpreted as the scenario in which the 101 gauge and disdrometers are on the leading storm edge with peak in- tensity while the $101 \mathrm{~b}$ gauge was on the trailing edge at that same instant. Furthermore, $101 \mathrm{~b}$ records the highest rain rate of $62.14 \mathrm{~mm} \mathrm{~h}^{-1}$, whereas the 101 gauge records only about a $10 \mathrm{~mm} \mathrm{~h}^{-1}$ peak rain rate. All of the instruments measured the 1913 UTC maximum at the same time. However, the peak rain rate for the two gauges, denoted by arrows in Fig. 3b, differ by more than $10 \mathrm{~mm} \mathrm{~h}^{-1}$.

\section{2) J-250 EvEnT}

The 7 September 1998 event started at 2022 and continued to 2228 UTC. The first part of the event was convective in nature and was followed by persistent stratiform precipitation. Although this event did not have a peak rain rate as high as that of the J-246 event, it brought more rain to the surface, as noted in Table 1. Figures $4 \mathrm{a}, \mathrm{b}$ represent the reflectivity and rain-rate time series, respectively. Even though the UHF profiler and the disdrometers estimate similar reflectivity time series, the WSR-88D differs significantly. The WSR88D measures a nearly uniform reflectivity with an average of $29 \mathrm{dBZ}$ for the most of the time duration that results in an underestimated rainfall. However, it estimates low rain rates at the beginning and middle of the event, at which times none of the surface-based instruments observed any rainfall.

For J-250, the two redundant gauges show well-synchronized measurements, which indicates that the difference in rain rates between the two gauges in the J246 event is not due to any systematic bias or instrument error but is due to real spatial variability of precipitation on the microscale.

\section{b. Pentad variability}

The pentad accumulations over the two networks are given in Table 2. September of 1998 is found to be wetter than August of 1998 over this region. In the first pentad (P1) of August, there is an appreciable amount

TABLE 2. Pentad rainfall accumulation during TEFLUN-B ( $R_{\text {av }}$ and $G_{\text {av }}$ are average radar and gauge accumulations, respectively).

\begin{tabular}{|c|c|c|c|c|c|c|}
\hline \multirow{2}{*}{$\begin{array}{c}\text { Pentad } \\
\text { No. }\end{array}$} & \multirow[b]{2}{*}{ Symbol } & \multirow[b]{2}{*}{ Starting date } & \multicolumn{2}{|c|}{ KSC network } & \multicolumn{2}{|c|}{ DRGN } \\
\hline & & & $R_{\mathrm{av}}$ & $G_{\mathrm{av}}$ & $R_{\mathrm{av}}$ & $G_{\mathrm{av}}$ \\
\hline 1 & P1 & 30 Jul 1998 & 1.69 & 2.26 & 29.5 & 31.15 \\
\hline 2 & P2 & 4 Aug 1998 & 4.67 & 39.17 & 5.6 & 46.87 \\
\hline 3 & P3 & 9 Aug 1998 & 27.6 & 20.33 & 28.52 & 21.3 \\
\hline 4 & $\mathrm{P} 4$ & 14 Aug 1998 & 18.82 & 17.4 & 17.12 & 8.89 \\
\hline 5 & P5 & 19 Aug 1998 & 42.79 & 54.25 & 49.94 & 68.77 \\
\hline 6 & P6 & 24 Aug 1998 & 0.13 & 0.05 & 2.16 & 1.06 \\
\hline 7 & $\mathrm{P} 7$ & 29 Aug 1998 & 3.75 & 2.84 & 1.8 & 1.96 \\
\hline 1 & $\mathrm{P} 1$ & 29 Aug 1998 & 18.95 & 18.97 & 0.56 & 1.09 \\
\hline 2 & $\mathrm{P} 2$ & 3 Sep 1998 & 52.93 & 61.46 & 27.95 & 25.54 \\
\hline 3 & $\mathrm{P} 3$ & 8 Sep 1998 & 2.38 & 1.16 & 1.1 & 0.42 \\
\hline 4 & P4 & 13 Sep 1998 & 40.1 & 62.91 & 36.66 & 61.32 \\
\hline 5 & P5 & 18 Sep 1998 & 50.31 & 56.25 & 33.19 & 64.63 \\
\hline 6 & P6 & 23 Sep 1998 & 41.38 & 44.92 & - & - \\
\hline
\end{tabular}


TABLE 3. Analysis of rainfall variation in DRGN clusters during TEFLUN-B (ID is gauge identification number and $R$ is rainfall accumulation).

\begin{tabular}{|c|c|c|c|c|c|c|}
\hline Month & Pentad & Cluster & ID & $R(\mathrm{~mm})$ & Mean & Std dev \\
\hline \multirow[t]{10}{*}{ Aug } & P5 & $101 \mathrm{C}$ & 101 & 54.6 & 55.2 & 3.6 \\
\hline & & & $101 b$ & 53.1 & & \\
\hline & & & 102 & 60.4 & & \\
\hline & & & 103 & 52.6 & & \\
\hline & & $112 \mathrm{C}$ & 112 & 72.3 & 74.3 & 2.7 \\
\hline & & & 114 & 73.2 & & \\
\hline & & & 115 & 77.4 & & \\
\hline & & $108 \mathrm{C}$ & $108 \mathrm{a}$ & 76.9 & 75.0 & 3.2 \\
\hline & & & $108 b$ & 71.3 & & \\
\hline & & & $108 \mathrm{c}$ & 76.8 & & \\
\hline \multirow[t]{10}{*}{ Sep } & P5 & $101 \mathrm{C}$ & 101 & 76.2 & 59.2 & 39.6 \\
\hline & & & $101 b$ & 77.9 & & \\
\hline & & & 102 & 82.8 & & \\
\hline & & & 103 & 0.0 & & \\
\hline & & $112 \mathrm{C}$ & 112 & 80.2 & 80.2 & 4.5 \\
\hline & & & 114 & 84.6 & & \\
\hline & & & 115 & 75.7 & & \\
\hline & & $108 \mathrm{C}$ & $108 \mathrm{a}$ & 43.6 & 29.2 & 17.4 \\
\hline & & & $108 b$ & 9.9 & & \\
\hline & & & $108 \mathrm{c}$ & 34.2 & & \\
\hline
\end{tabular}

of rainfall over the DRGN, but the KSC network was almost dry. This result indicates the spatial variability that is possible in shorter timescales. A similar type of variability is observed in P1 and P2 of September. In the case of P1, the KSC network observed some rainfall, whereas the DRGN is dry; in P2, the average rainfall over KSC is much higher (about 2 times) than that of DRGN. However, P4 and P5 of both months show nearly uniform rainfall over both networks. Another important observation is that, for more or less uniform rainfall over the networks, radar- and gauge-estimated rainfall matched closely, but whenever there is notable spatial variation, the radar and gauge estimates start to differ.

In both August and September of 1998, P5 was the wettest pentad. The driest pentad in August is P6, and that in September is P3. Figures 5 and 6 represent the wettest-pentad accumulation maps for August and September, respectively. It is observed from these maps that both the radar and gauge measured a similar pattern of spatial variability during the pentad. For the radar, the gradient is flatter, whereas, for the gauge observations, there are some sharp gradients among the adjacent cells. This result is expected because of the large difference in the sampling volume of these two instruments. The radar is found to underestimate the rainfall in most cases.

If we further investigate the subpixel-scale observation by gauges in DRGN clusters, it is found that significant variability is observed there even for the wettest pentads. The results of subpixel-scale analysis are given in Table 3.

\section{c. Monthly variability}

The histograms of monthly rainfall accumulation over the KSC network and DRGN for August and September
TABLE 4. Monthly decorrelation length over KSC and DRGN.

\begin{tabular}{clr}
\hline \hline Month & Site & $d(\mathrm{~km})$ \\
\hline Aug & KSC & 19.10 \\
& DRGN & 9.01 \\
Sep & KSC & 20.49 \\
& DRGN & 9.70 \\
\hline
\end{tabular}

of 1998 are presented in Figs. 7 and 8, respectively. The hatched columns are for gauge observation and the solid columns are for radar observation. The histograms represent the distribution of total monthly rain accumulation over the entire network. For August, the gauges in the KSC network (Fig. 7a) measured rainfall accumulation distributed over 112.5-212.5 mm, with a most probable value of $137.5 \mathrm{~mm}$. For the same month, the radar-observed accumulation was within the 112.5137.5-mm range, with a nearly uniform distribution. The radar also noted some higher accumulation with lower frequencies. For August over the DRGN (Fig. 7b), gauges observed accumulation that was normally distributed between 62.5 and $162.5 \mathrm{~mm}$, with a mean value of 112.5 $\mathrm{mm}$. The radar shows a similar distribution, with a skew around $87.5 \mathrm{~mm}$.

KSC gauges measured (Fig. 8a) a nearly uniform distribution of monthly accumulation within the range of 100.0-325.0 mm for September, whereas the radar observation is distributed over a narrower range, with a peak around $250.0 \mathrm{~mm}$. DRGN accumulations (Fig. 8b) were also uniformly distributed over a range of 100$175 \mathrm{~mm}$. However, the radar over DRGN observed a nearly homogeneous monthly accumulation field, with $75 \%$ of it within the range of $150-175 \mathrm{~mm}$ and the remaining $25 \%$ of measured accumulation within the 125-150-mm range.

These histograms show that the monthly networkaveraged rainfall measured by two instruments is close, but there is significant variability over the entire network.

\section{DECORRELATION OF PRECIPITATION}

To understand the spatial variability of precipitation quantitatively, the decorrelation length of precipitation is estimated from the pentad and monthly rainfall accumulation maps. For that purpose, autocorrelation of the observed network rainfall field is carried out using standard routines. Spatial autocorrelation in two dimensions is obtained by cross correlation of the matrix $\mathbf{R}(x$, $y$ ) with itself using a lag of $\Delta x, \Delta y$. Thus, the resultant size of the autocorrelation matrix for an input matrix of the size $M \times N$ is $(2 M+1) \times(2 N+1)$, with an equal number of positive and negative lags in both directions. Then, $\Delta y=0$ lag correlation coefficients are plotted for positive lags along the $x$ direction and $\Delta x=0$ lag correlation coefficients are plotted for positive lags along the $y$ direction. Each lag along $x$ or $y$ corresponds to a $2-\mathrm{km}$ distance. From these plots, the length $(\mathrm{km})$ at 


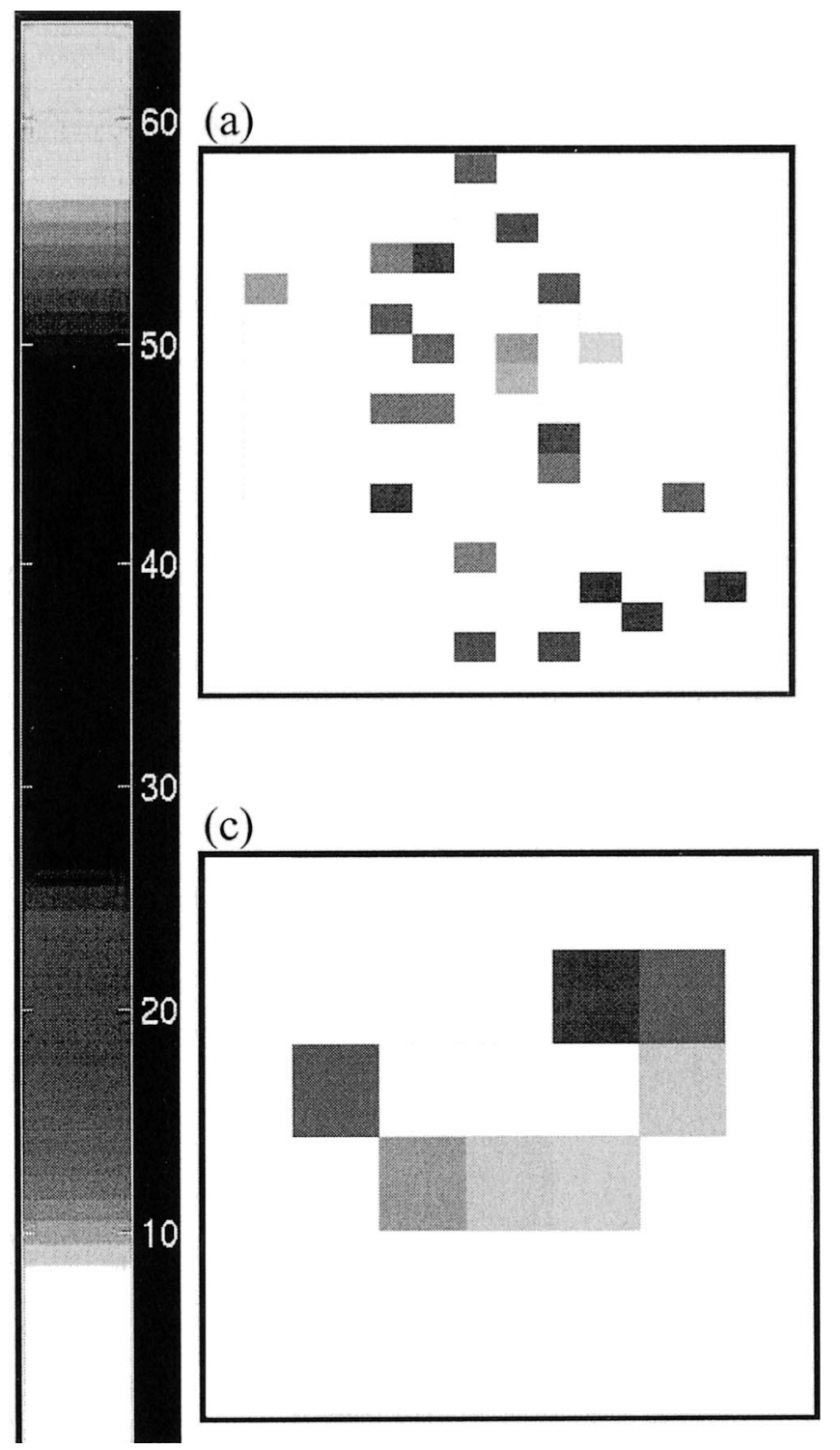

(b)

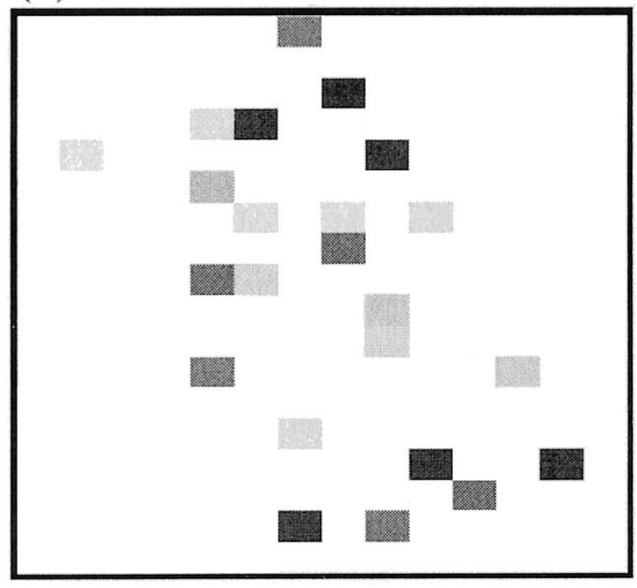

(d)

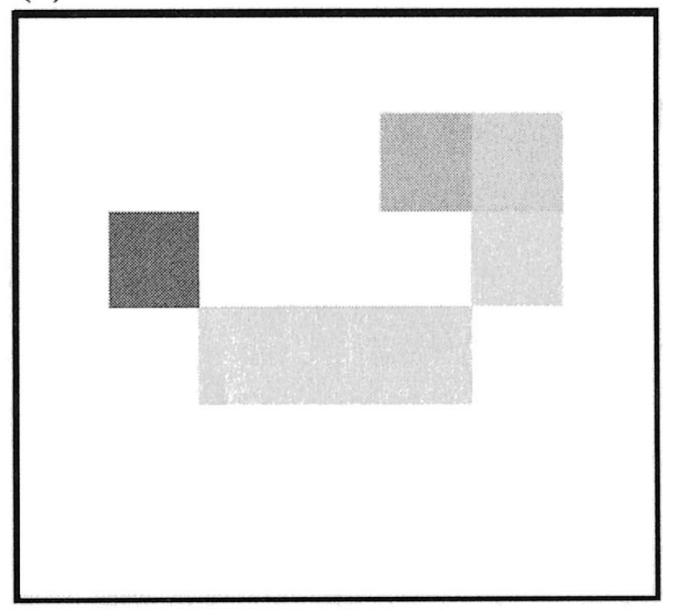

FIG. 5. Aug 1998 wettest pentad (P5) accumulation map over KSC from (a) radar and (b) gauge and over DRGN from (c) radar and (d) gauge.

which the correlation is dropped by 1/e is estimated along the $x\left(d_{x}\right)$ and $y\left(d_{y}\right)$ directions. The decorrelation distance is calculated as

$$
d=\sqrt{d_{x}^{2}+d_{y}^{2}} .
$$

Figure 9 shows the variation of decorrelation length over different networks at the pentad timescale. Decorrelation lengths for the monthly maps are listed in Table 4.

The shape and size of the sampling area limits the use of autocorrelation statistics. Information collected from a larger area represents a much broader picture and statistically smooths out any relatively finer-scale variability (Odland 1988). The KSC network has a larger area and, as a consequence, shows a smoother map, evident from longer decorrelation lengths, as compared with DRGN. Another important observation is that the monthly decorrelation length is higher during September than during August. This result is consistent with the fact that during the month of September there is widespread rainfall over Florida as a consequence of Hurricanes George and Bonnie, thereby creating a more homogeneous monthly accumulation map for the KMLB radar.

\section{d. Effect of convective/stratiform (CS) classification}

As mentioned in section 3a, the J-246 event was a typical convective shower. Because the radar samples every 5-6 min, it missed the peak of the event and consequently underestimated the total accumulation by 


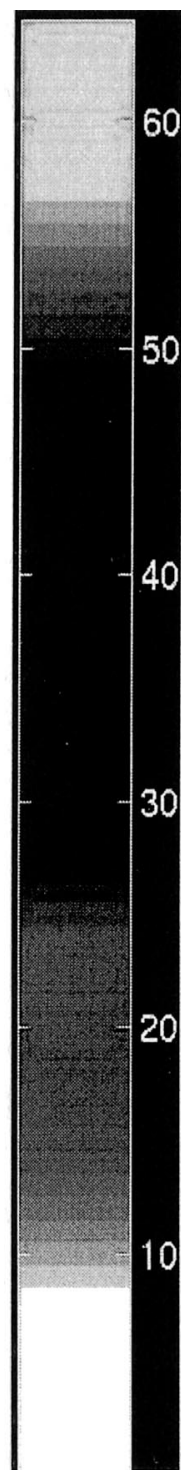

(a)

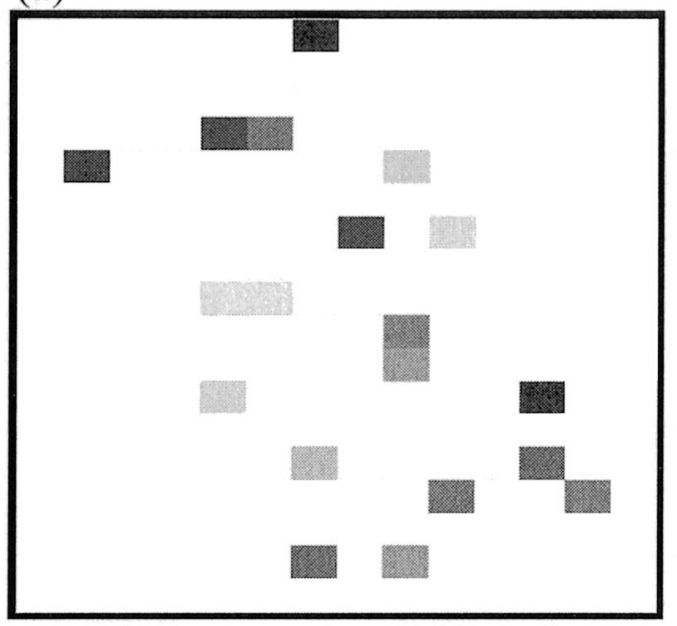

(c)

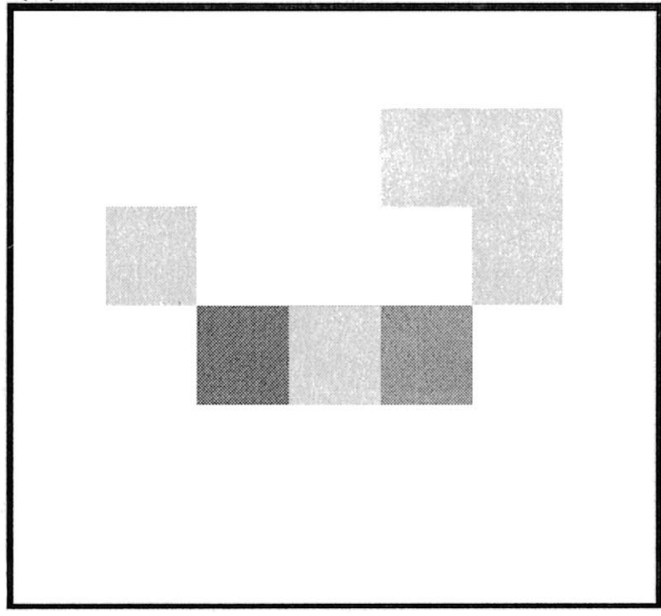

(b)

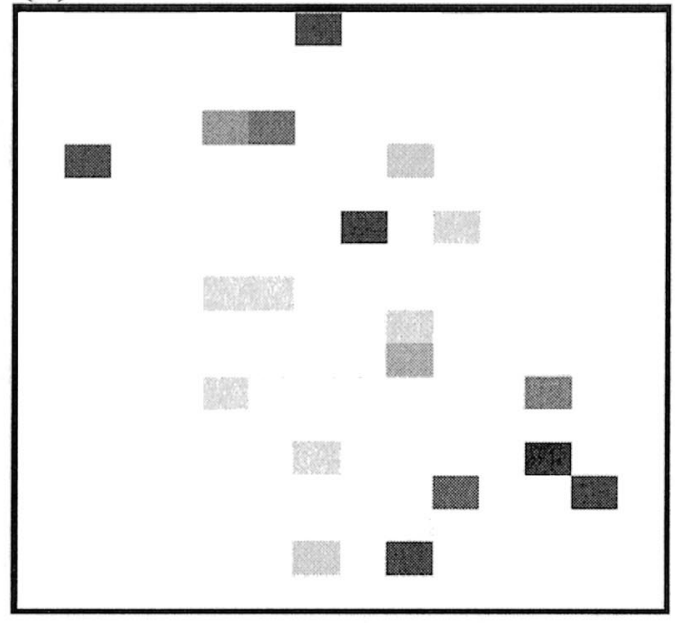

(d)

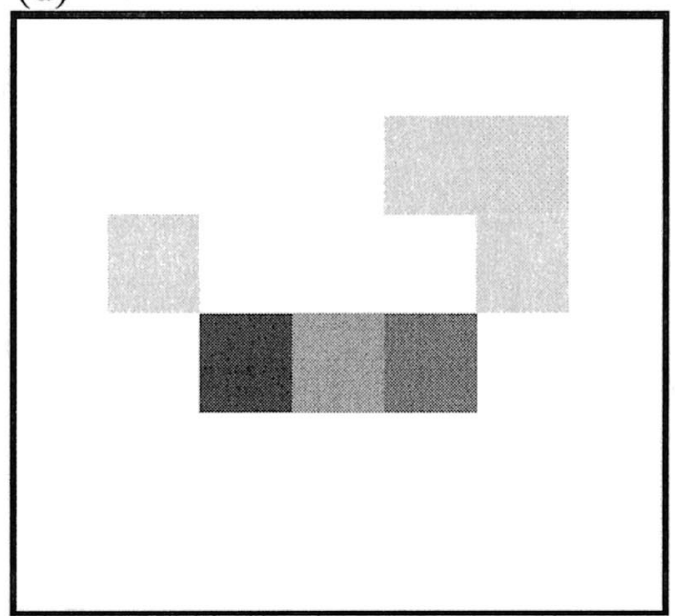

FIG. 6. Same as Fig. 5 but for Sep 1998.

$38 \%-40 \%$ in comparison with other surface observations. On the other hand, J-250 had a significant stratiform component, which presented a more spatially and temporally homogeneous precipitation field to the radar. As a result, the difference between the surface-observed total accumulation and the radar estimate is less (about $14 \%-20 \%)$. This illustrates the fact that an instantaneous (or event scale) comparison of radar with surface observation depends greatly on the type of the storm in question.

The effect of CS classification decreases with increasing timescale. In the case of pentad accumulation there are some effects as mentioned earlier, but in the case of monthly accumulation the effect is negligible. During August of 1998, 84\% of rainfall over the region of interest was convective in nature and $16 \%$ was stratiform. For September of 1998, the figures are $82 \%$ and
$18 \%$, respectively. A simple comparison of bulk radar accumulation with gauge accumulation for different gauge networks in the KMLB radar mask has been done separately for convective, stratiform, and combined cases. The bulk radar-to-gauge ratios are listed in Table 5. It is observed, for both the months, that the total accumulation is dominated by the convective fraction. This is an obvious consequence of the fact that more than $80 \%$ of the precipitation is convective in nature for the observation period.

\section{Spatial and temporal matching method}

The spatial variability noted in the previous section suggests that whenever any study between two sensors with different resolution is carried out, it is important to match them properly in space and time to obtain a 

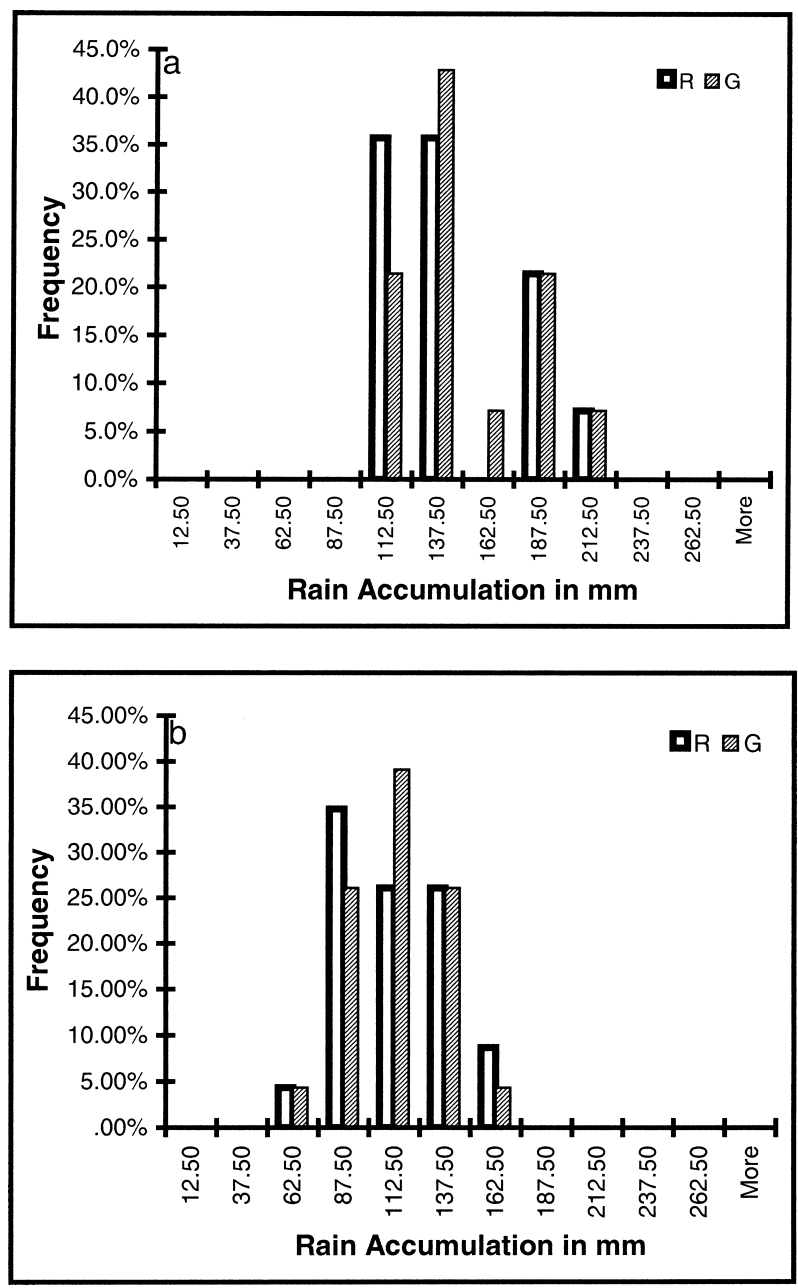

FIG. 7. Histogram of monthly rain accumulation for Aug 1998 over the (a) KSC network and (b) DRGN.

meaningful comparison. This is particularly important in the case of convective rainfall, as is predominant during the period of study. In this section, an attempt has been made to search for a method of combining the radar with surface observations that will yield a better comparison. At first, spatial matching of radar to surface measurements at the monthly timescale is attempted. For this case, we choose a monthly observation period, because, at this scale, we need not worry about asynchronous temporal sampling.

\section{a. Spatial filtering}

Two different approaches are tested to obtain spatial matching. One is to smooth the radar observation to create a more homogeneous map over the network and then to compare the smoothed radar data to surface data. The other approach is to magnify or zoom in on the radar image using an interpolation technique to see the subpixel-scale variation and to compare the interpolated radar data over the gauge to the actual surface obser-
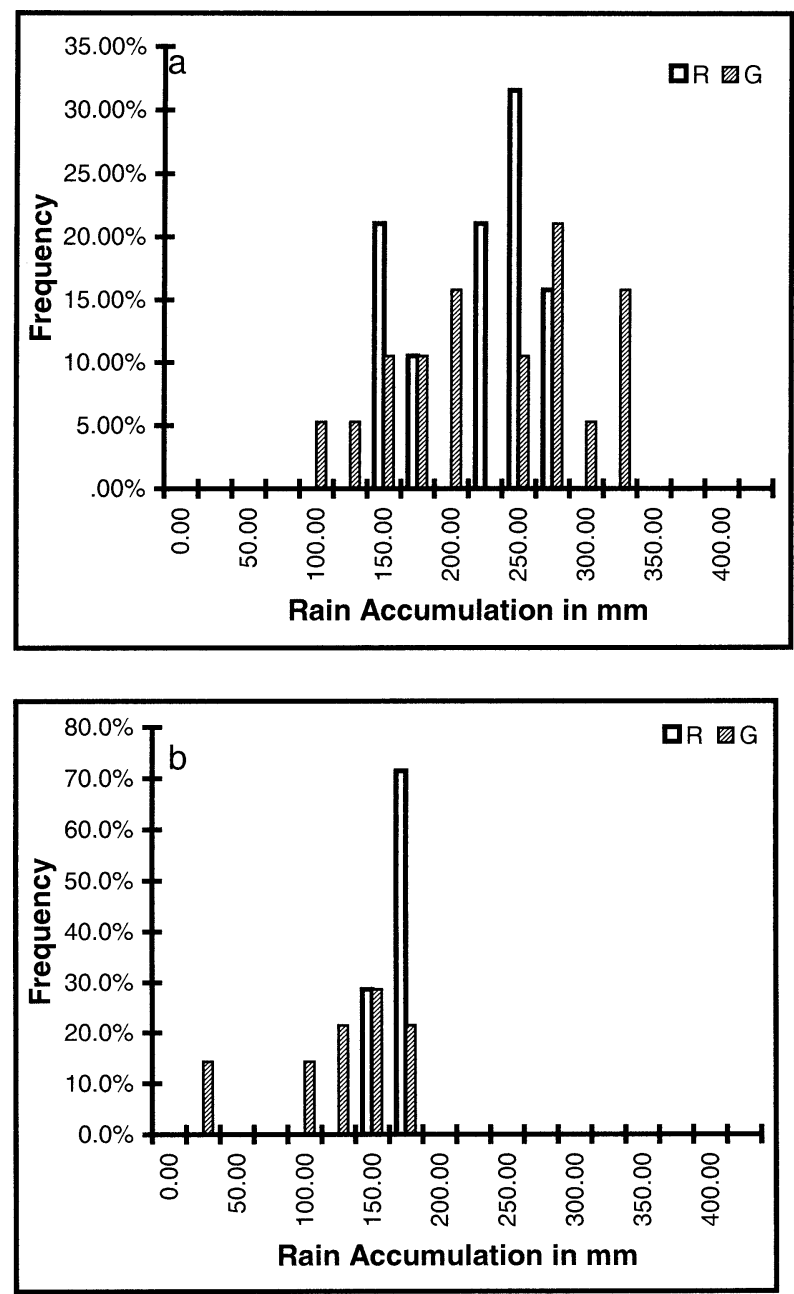

FIG. 8. Same as Fig. 7 but for Sep 1998.

vation. Both of these methods used a sliding-window spatial filtering technique. Figure 10 illustrated this sliding-window approach. Consider the $5 \times 7$ data array on the left-hand side. A $3 \times 3$ kernel is convoluted with the $3 \times 3$ data array beneath it, and the result of the

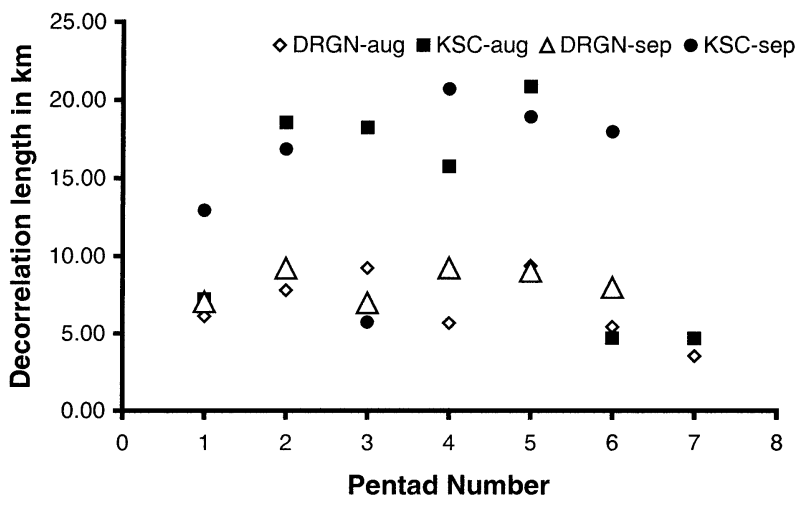

FIG. 9. Decorrelation length from pentad accumulation map. 
TABLE 5. Bulk radar-to-gauge accumulation ratio for different types of rainfall ( $\Sigma R$ and $\Sigma G$ are the bulk radar and gauge rainfall estimates, respectively).

\begin{tabular}{|c|c|c|c|c|}
\hline \multirow[b]{2}{*}{ Month (1998) } & \multirow[b]{2}{*}{ Network } & \multicolumn{3}{|c|}{ Bulk ratio: $\Sigma R / \Sigma G$} \\
\hline & & Convective & Stratiform & Combined \\
\hline \multirow[t]{4}{*}{ Aug } & $\mathrm{KSC}$ & 0.86 & 1.05 & 0.89 \\
\hline & South Florida gauge network & 1.15 & 1.10 & 1.14 \\
\hline & $\begin{array}{l}\text { St. John Water Management District } \\
\text { gauge network }\end{array}$ & 0.96 & 0.85 & 0.94 \\
\hline & All networks & 0.99 & 1.00 & 0.99 \\
\hline \multirow[t]{4}{*}{ Sep } & $\mathrm{KSC}$ & 0.85 & 0.94 & 0.87 \\
\hline & South Florida gauge network & 1.09 & 1.03 & 1.08 \\
\hline & $\begin{array}{l}\text { St. John Water Management District } \\
\text { gauge network }\end{array}$ & 1.10 & 1.02 & 1.09 \\
\hline & All networks & 1.01 & 0.99 & 1.01 \\
\hline
\end{tabular}

convolution is placed at the central pixel (checkered box) location in the new filtered image (shaded on the right-hand-side array). This operation is repeated by sliding the window, first from left to right and then from top to bottom, to create the new filtered image. The border pixels are kept unaltered. Note here that no change is made to the original data array during this sliding-window technique. In matrix notation it can be written as $\tilde{O} \mathbf{A}=\mathbf{B}$, where $\tilde{O}$ signifies the filtering operation, $\mathbf{A}$ is the data array used, and $\mathbf{B}$ is the new filtered data array. To apply the filtering over the entire network region, a slightly larger area is considered for this analysis.

\section{1) SMoothing APPROACHeS}

Three different smoothing techniques are tested.

\section{(i) Quad-smoothing technique (QS)}

In this method the $3 \times 3$ window is again split into 4 quads (see illustration in Fig. 11). The arithmetic average of each quad is performed and is denoted by $\overline{Q_{i}}$ for the $i$ th quad. The average of the central pixel value (number 5) with the four quad averages is substituted as the smoothed estimate of pixel 5 (Datta et al. 2000). This method is referred to as QS in the rest of the paper. It is equivalent to using a weighted average with the 3 $\times 3$ kernel:

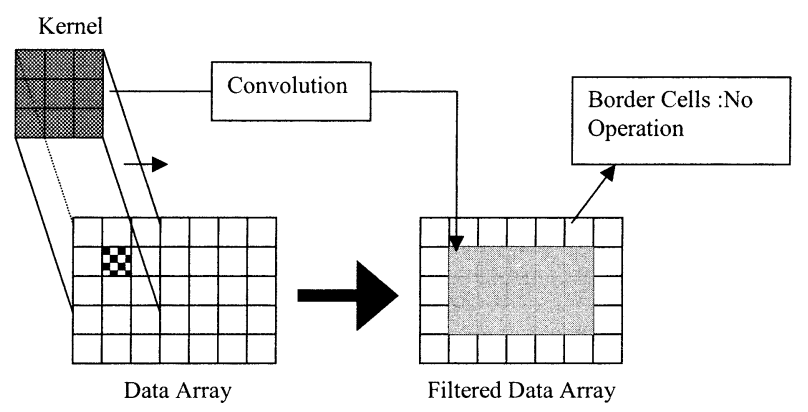

FIG. 10. Illustration of the sliding-window technique.

$$
\left[\begin{array}{ccc}
\frac{1}{20} & \frac{2}{20} & \frac{1}{20} \\
\frac{2}{20} & \frac{8}{20} & \frac{2}{20} \\
\frac{1}{20} & \frac{2}{20} & \frac{1}{20}
\end{array}\right]
$$

\section{(ii) Median filtering (MF)}

Smoothing using median filtering (MF) is also tried. In MF, accumulations in the $3 \times 3$ window are first sorted, and then the median of those nine observations is substituted for the central pixel value. Suppose we have a $3 \times 3$ data array, such as

$$
\left[\begin{array}{ccc}
9 & 17 & 3 \\
25 & 2 & 7 \\
18 & 15 & 10
\end{array}\right] .
$$

If we sort these nine values, we will have the set $\{2,3$, $7,9,10,15,17,18,25\}$. The median value of this array is 10 , which is substituted for the central pixel.

This is a nonlinear filtering technique (Jain 1989) used mainly to remove any noisy pixel that shows a spike in the scene. This kind of filter might work well in the case of AP-contaminated precipitation echoes present in the map, which could not be corrected using the

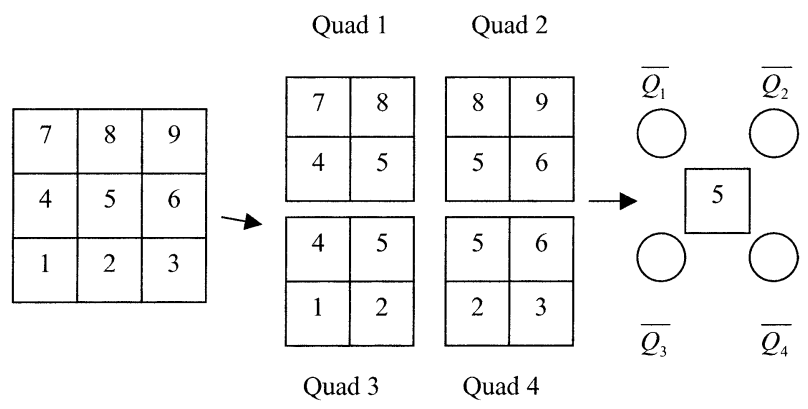

FIG. 11. Illustration of quad smoothing. 
current radar quality-control (Robinson et al. 1999) method.

\section{(iii) Trimming filter (TF)}

In this method, the two lowest and two highest values from the sorted set of nine observations are removed first, and then the average of the five central values is substituted for the central pixel value. This is a hybrid filter known as an $\alpha$-trimmed mean filter (Efford 2000). In the current case, $\alpha=2$. If we consider the same matrix as in MF, then by trimming the two lowest and two highest values of the sorted set we will have the central subset $\{7,9,10,15,17\}$. The average of this subset is 11.6 , which is substituted for the center pixel value.

\section{2) INTERPOLATION APPROACH}

Another approach used in matching radar to gauge data is to magnify or zoom in on the radar data to resolve the subpixel-scale variability using a two-dimensional interpolation technique. Radar data in a $3 \times 3$ window over the gauge are used for that purpose. A Cartesian coordinate system is used with its origin at the center of the central pixel of the $3 \times 3$ set. The relative location of the gauge $(x, y)$ with respect to that coordinate system is then estimated. Lagrangian polynomial interpolation of the radar data in two dimensions is performed in the following manner. First, interpolation along the $x$ axis is carried out, yielding a column vector $\mathbf{I}$ as

$$
I_{i}\left(x, y_{i}\right)=\sum_{n} R\left(x_{n}, y_{i}\right) L_{n}(x),
$$

where

$$
L_{n}(x)=\frac{\prod_{m \neq n}\left(x-x_{m}\right)}{\prod_{m \neq n}\left(x_{n}-x_{m}\right)}
$$

The components of $\mathbf{I}$ are interpolated along $y$ as

$$
R(x, y)=\sum_{i} I\left(x, y_{i}\right) L_{i}(y)
$$

where

$$
L_{i}(y)=\frac{\prod_{m \neq i}\left(y-y_{m}\right)}{\prod_{m \neq i}\left(y_{i}-y_{m}\right)} .
$$

This is referred to as the LP method.

\section{3) Evaluation of DifFerent Methods}

Monthly radar estimates from these four different techniques and also from the observed center pixel observation (referred to as $O$ ) are compared with the surface gauge measurement. To find out which method is working best, only quality gauges from the KSC net-
TABLE 6. Evaluation score of different spatial matching methods ( $O$ is observed, QS is quad smoothing, LP is interpolation using Lagrangian polynomial, MF is median filter, and TF is trimming filter).

\begin{tabular}{cccccc}
\hline \hline $\begin{array}{c}\text { Month } \\
(1998)\end{array}$ & $O$ & QS & LP & MF & TF \\
\hline Aug & 41 & 37 & 54 & 22 & 23 \\
Sep & 45 & 36 & 47 & 37 & 39 \\
\hline
\end{tabular}

work and DRGN are used. A point system based on the following criteria is used for the evaluation purpose:

Criterion 1) At how many $(P)$ individual gauge locations does this method yield a radar estimate closest to a gauge observation? Any one of the four methods can give better matching than the others, depending on the individual distribution of precipitation and/or noise level in the radar or gauge data; $P$ is basically the measure of probability of the method yielding a better radar estimate. The method with the highest $P$ is given the highest number of points (5), and every method will lose 1 point as it goes down in the hierarchy by one position. The methods yielding equal $P$ values will receive the same number of points.

Criterion 2) The difference of mean (DM) between radar and gauge network totals over each individual network is found. The method yielding the lowest DM is given the highest number of points, and the rest of the grading system will remain the same as in criterion 1.

Criterion 3) The difference of variance (DV) between radar and gauge observations over the entire network is calculated. In this case, the method yielding the lowest DV will earn the highest number of points.

Criterion 4) The average radar-to-gauge ratio (R/G) is found over each network using each method. The method that will yield the best average R/G will be assigned the highest number of points.

Criterion 5) The bulk R/G is formulated by combining the two networks. This metric is the ratio of radar total from all of the DRGN and KSC AQC gauges to the corresponding gauge total. Here again, the method yielding the best bulk R/G will be assigned the highest number of points.

The result of the above analysis is shown in Table 6. It is found that the LP method yields better results for both months. One way to test the performance of the LP method is to apply it to instantaneous or, at least, event-scale estimates. At that finer time resolution, the question of asynchronous sampling by different sensors comes into question. A temporal matching technique is described in the next section to account for this problem.

\section{b. Temporal matching method}

Zawadzki (1975) has noted that the smoothing of gauge data over an optimum time interval improves the 
TABLE 7. Performance of different temporal matching methods for rain-rate comparison (101 is gauge at DRGN 101 site, 101b is redundant gauge next to $101,2 \mathrm{DVD}$ is two-dimensional video disdrometer, JWD is Joss-Waldvogel-type disdrometer, and All is sum of points from all instruments).

\begin{tabular}{lccccc}
\hline \multicolumn{1}{c}{ Method } & 101 & $101 \mathrm{~b}$ & 2DVD & NWD & All \\
\hline Resample & 15 & 14 & 13 & 14 & 56 \\
Avg & 12 & 13 & 14 & 15 & 54 \\
Median filter & 14 & 14 & 19 & 16 & 63 \\
\hline
\end{tabular}

gauge-to-radar comparison. In the current work, the average interval (5 $\mathrm{min}$ ) of a consecutive WSR-88D volume scan is taken as that optimal interval. Three different approaches are used here, 1) resampling all surface observations at the time of radar scan, 2) averaging the surface observation in a 5-min window around the radar scan time, and 3) taking a median of observations in a 5-min window around the radar scan time. A statistical hypothesis testing for matching variances and means (with respect to the WSR-88D estimate) is performed. Then, a point-based evaluation of the method yielding better correspondence to the WSR-88D observation is determined for each instrument using the following criteria:

1) correlation between the two sets of estimates,

2) difference in variance,

3) difference in mean,

4) result of variance hypothesis (level of significance: $95 \%$ ), and

5) result of mean hypothesis (level of significance: $95 \%)$.

Each criterion in 1-3 above has a maximum of 3 points, and a method loses 1 point as it goes down by one position. Criteria 4 and 5 each earn 1 or 0 points, depending on whether the variances or means are close or significantly different. The results of this analysis are given in Tables 7 and 8 .

It is found that smoothing the surface observations around the WSR-88D scan time using median filtering gives the best estimate. The median filter removes any spike or impulsive noise in the surface observation and improves the radar-to-surface comparison. A sequential combination of this spatial and temporal matching technique is found to improve the comparison between radar and surface observations (Figs. 12 and 13).

\section{Concluding remarks}

This paper presents a study of spatial variability of precipitation at event, pentad, and monthly timescales. In analyzing the subpixel-scale gauge clusters in the DRGN, it is found that, even for a single-event observation, there might exist some microscale variability of precipitation.

To observe the network-scale variability, the decorrelation length of precipitation is estimated. It is found
TABLE 8. Performance of different temporal matching methods for reflectivity comparison (2DVD is two-dimensional video disdrometer, JWD is Joss-Waldvogel-type disdrometer, UHF is ultrahigh-frequency profiler, and All is sum of points from all instruments).

\begin{tabular}{lcccc}
\hline \multicolumn{1}{c}{ Method } & 2DVD & JWD & UHF & All \\
\hline Resample & 12 & 14 & 18 & 44 \\
Avg & 12 & 12 & 12 & 36 \\
Median filter & 18 & 18 & 18 & 54 \\
\hline
\end{tabular}

that over the KSC region this length is about $20 \mathrm{~km}$ and over DRGN it is about $10 \mathrm{~km}$. It is also observed that over a pentad timescale, the decorrelation length varies depending on the type of rainfall during the specific pentad. Pentads associated with widespread precipitation events, such as rainbands from a hurricane, show longer decorrelation lengths, as expected.

The following method is found to yield the best matching of radar to gauge observation:

1) Interpolate the radar observation, using bipolynomial interpolation, over the point of the surface where the gauge is located. This is similar to magnifying the radar image to see the details on a subpixel scale.

2) Smooth the surface observation timeseries using a median filter around the radar sampling time in a 5min window and combine the smoothed gauge observation with the interpolated radar observation for comparison or calibration. By using a median filter, it is possible to remove any noise in the surface
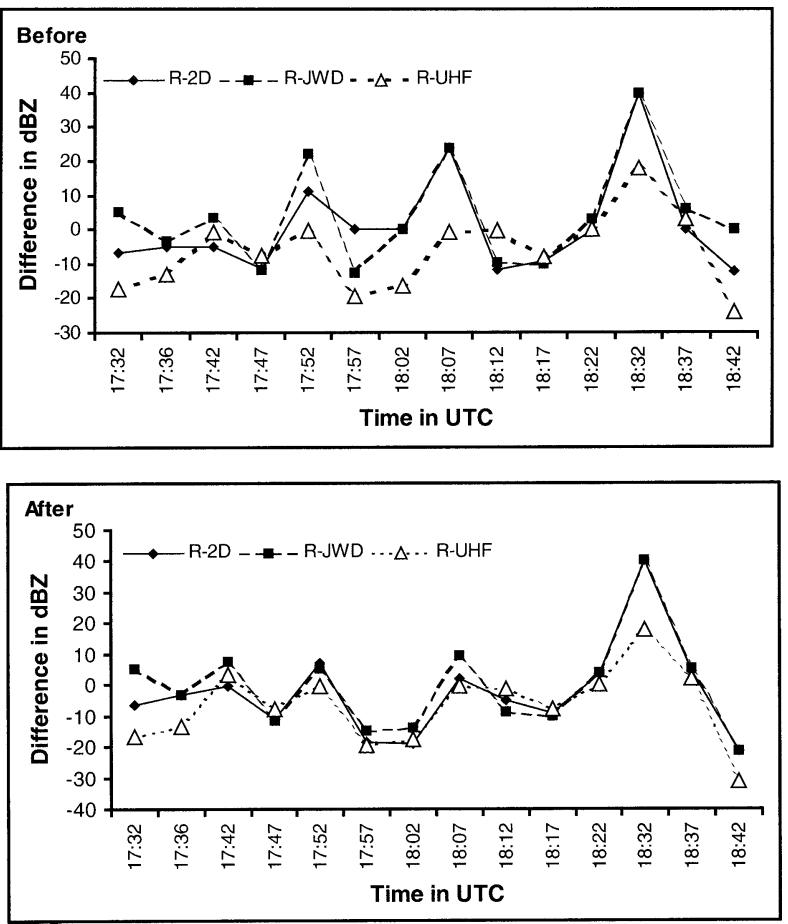

FIG. 12. Difference in reflectivity between surface instruments and WSR-88D (top) before and (bottom) after spatial-temporal filtering over the DRGN region for the J-246 event. 

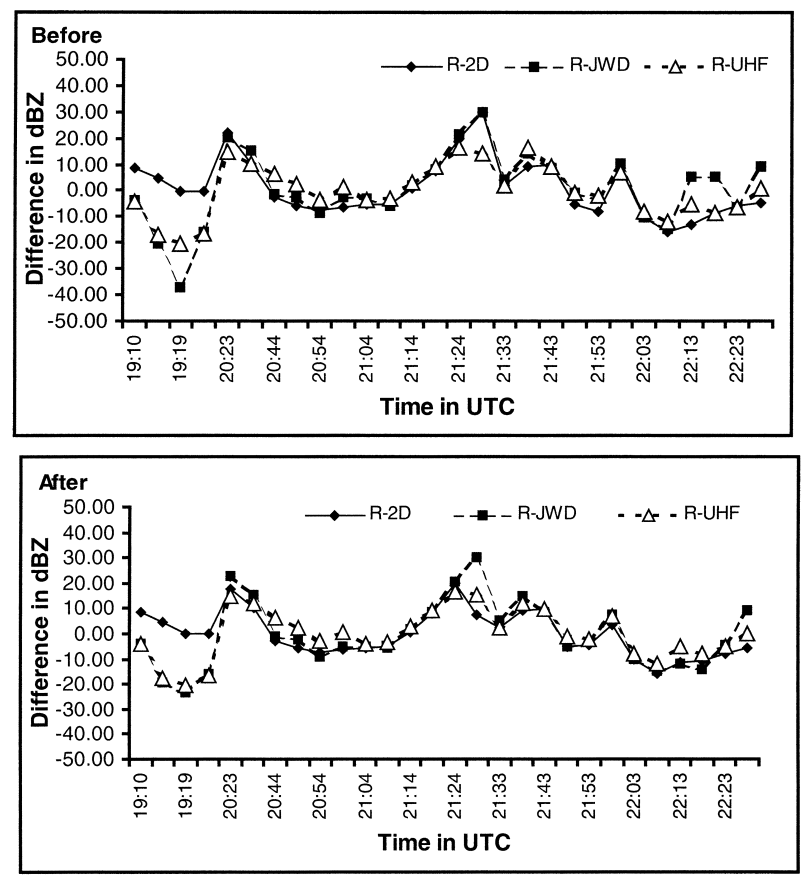

FIG. 13. Same as Fig. 12 but for the J-250 event.

observation. Smoothing in a 5-min window around the radar sampling time enables us to account for the time delay associated with the time taken by the radar-observed rain to reach the ground.

This technique is also found to yield a better result when compared with other surface-based observations made during TEFLUN-B. Even after this spatial-temporal matching, it is observed that there exists a fixed bias between the WSR-88D and other surface-based observations. This systematic bias between radar and surface observation might be the effect of vertical variability of rainfall between the altitude at which radar performs its observations and the ground (Roy et al. 2000). Note that the spatial matching performed in this paper considered only variability in the horizontal, and no adjustment was made for the rain variability over the altitude between the radar measurement and surface.

Further, note that validation of satellite observations with ground-based radar estimates may exhibit similar spatial-temporal resolution differences. The satellite observes at a larger spatial resolution and at a very low sampling frequency with respect to the ground-based radar. The suggested spatial-temporal matching technique should be tested against comparisons of satellite to surface radar rain rates.

Acknowledgments. The authors thank the operational TRMM GV data-processing team for providing the necessary radar data products. We also extend our sincere appreciation to Drs. Kenneth Gage and Christopher Williams of the NOAA Aeronomy Laboratory for their operational responsibilities with JWD disdrometers and the
UHF profiler during the TEFLUN-B campaign. We acknowledge the Central Florida Remote Sensing Laboratory for installing and maintaining the DRGN during the TEFLUN-B field campaign. We are thankful to Professor Raymond Hoff, director of JCET, for his valuable comments and suggestions during the preparation of this manuscript. We are also thankful for the useful comments and suggestions from the three unknown reviewers, which helped to improve the manuscript. This research was partially funded by a grant from the NASA Goddard Space Flight Center Tropical Rainfall Measuring Mission Project.

\section{REFERENCES}

Atlas, D., D. Rosenfield, and A. R. Jameson, 1997: Evolution of radar rainfall measurements: Steps and mis-steps. Weather Radar Technology for Water Resources Management, B. Braga and O. Massambani, Eds., UNESCO, 1-60.

Battan, L. J., 1973: Radar Observation of the Atmosphere. University of Chicago Press, 323 pp.

Brandes, E. A., G. Zhang, and J. Vivekanandan, 2002: Experiments in rainfall estimation with a polarimetric radar in a subtropical environment. J. Appl. Meteor., 41, 674-685.

Datta, S., B. Roy, and B. S. Ferrier, 2000: Quantitative estimation of some possible errors associated with radar derived monthly rain maps and a scheme for spatial averaging of radar accumulation. Eos, Trans. Amer. Geophys. Union, 81, S224.

Efford, N., 2000: Digital Image Processing: A Practical Introduction Using Java. Addison-Wesley, 340 pp.

Habib, E., and W. F. Krajewski, 2002: Uncertainty analysis of the TRMM ground-validation radar-rainfall products: Application to the TEFLUN-B field campaign. J. Appl. Meteor., 41, 558-572.

Jain, A. K., 1989: Fundamentals of Digital Image Processing. Prentice Hall, $350 \mathrm{pp}$.

Joss, J., and A. Waldvogel, 1990: Precipitation measurement and hydrology. Radar in Meteorology, D. Atlas, Ed., Amer. Meteor. Soc., 577-600.

Kummerow, C., and Coauthors, 2000: The status of the Tropical Rainfall Measuring Mission (TRMM) after two years in orbit. J. Appl. Meteor., 39, 1965-1982.

Le Bouar, E., J. Testud, and T. D. Keenan, 2001: Validation of the rain profiling algorithm "ZPHI" from the C-band polarimetric weather radar in Darwin. J. Atmos. Oceanic Technol., 18, 18191837.

Marks, D. A., M. S. Kulie, M. Robinson, B. S. Ferrier, and E. Amitai, 1999: Standardized reference rainfall products used in TRMM ground validation efforts. Preprints, 29th Int. Conf. of Radar Meteorology, Montreal, QC, Canada, Amer. Meteor. Soc., 744747.

Neff, E. L., 1977: How much rain does a rain gauge? J. Hydrol., 35, 213-220.

Odland, J., 1988: Spatial Autocorrelation. SAGE Publications, 87 pp.

Robinson, M., D. A. Marks, M. S. Kulie, and B. S. Ferrier, 1999: Seasonal characteristics of non-meteorological radar reflectivity returns in east central Florida and their impact on TRMM ground validation. Preprints, 29th Int. Conf. of Radar Meteorology, Montreal, QC, Canada, Amer. Meteor. Soc., 740-743.

Roy, B., S. Datta, W. L. Jones, and T. Kasparis, 2000: On utilization of NEXRAD scan strategy information to infer discrepancies associated with radar and rain gauge surface volumetric rainfall accumulation. Eos, Trans. Amer. Geophys. Union, 81, F162.

Tokay, A., A. Kruger, and W. F. Krajewski, 2001: Comparison of drop size distribution measurements by impact and optical disdrometers. J. Appl. Meteor., 40, 2083-2097.

Zawadzki, I. I., 1975: On radar-raingauge comparison. J. Appl. Meteor., 14, 1430-1436. 